\title{
Individual differences in highly skilled visual perceptual-motor striking skill
}

\author{
Sean Müller • John Brenton • Alasdair R. Dempsey • \\ Allen G. Harbaugh • Corinne Reid
}

Published online: 27 March 2015

(C) The Psychonomic Society, Inc. 2015

\begin{abstract}
Expertise studies into visual perceptual-motor skills have mainly focused their investigation upon group comparisons rather than individual comparisons. This study investigated the pick-up of visual information to time weight transfer and bat kinematics within an exemplar group of striking sport experts using an in situ temporal occlusion paradigm. Highly skilled cricket batsmen faced bowlers and attempted to strike delivered balls, whilst their vision was either temporally occluded through occlusion glasses prior to ball bounce or not occluded (control condition). A chronometric analysis was conducted on trials in the occlusion condition to quantify the pick-up of visual information to time biomechanical variables. Results indicated that initiation of weight transfer and bat downswing, as well as bat downswing completion, was significantly different between some individual batsmen. No significant difference was found between individual batsmen for time of weight transfer completion. Unexpectedly, it was found that achievement of the goal to strike delivered balls, that is, the frequency of bat-ball contacts was not significantly different between batsmen. Collectively, the findings indicate that individual differences exist in the coordination pattern of a complex whole body visual perceptual-motor skill, but these different patterns are used to achieve a similar outcome, which is known as motor equivalence.
\end{abstract}

Keywords Individual differences · Visual perceptual-motor skill $\cdot$ Motor equivalence $\cdot$ Striking sports

S. Müller $(\bowtie) \cdot J$. Brenton · A. R. Dempsey $\cdot$ C. Reid

School of Psychology and Exercise Science, Murdoch University, 90

South Street, Murdoch, Perth, Australia 6150

e-mail: s.muller@murdoch.edu.au

A. G. Harbaugh

School of Education, Boston University, Boston, MA, USA
It is commonplace for expertise studies into human visual perceptual-motor skill performance to focus their investigation upon comparison of a group of experts (or highly skilled individuals) to a group of less skilled individuals (Yarrow, Brown, \& Krakauer, 2009). For example, studies have reported that a group of experienced surgeons completed a virtual laparoscopic task faster and fixated target locations longer than a group of novices (Wilson et al., 2010). A multidisciplinary driving test, including a hazard perception component revealed a group of safe drivers identified potential hazards quicker than unsafe drivers (Wood, Horswill, Lacherez, \& Anstey, 2013). Longitudinal assessment using a flight simulator revealed that a group of general aviation expert pilots had better flight summary scores and better execution of aviation communications than a group of less skilled pilots (Taylor, Kennedy, Noda, \& Yesavage, 2007). A group of expert law enforcement officers shot more accurately and made fewer decision errors than a group of less skilled officers (Vickers \& Lewinski, 2012). A group of expert karate athletes were capable of anticipating an opponent's attack to block better than a group of near-expert karate athletes (Rosalie \& Müller, 2013). This type of group design implies that there is a model of visual perceptual-motor skill expertise relative to the variable(s) that are measured. Group designs, however, can mask individual differences that may exist in expert visual perceptual-motor skill in sport and other tasks.

The field of sport expertise, which is the focus of this study, traditionally has involved the investigation of athletes (e.g., performers such as baseball or cricket batters) who have reached a high skill level of competition (e.g., international or national level) in a specific sport compared with less-skilled individuals who have reached a lower level of competition (e.g., club level) (Müller \& Abernethy, 2012). This type of skill group comparison has been conducted to determine what factor(s) differentiate and limit expertise, such as the capability to pick-up visual information for anticipation. Perceptual- 
motor anticipation, which is relevant to this study, involves the capability of the performer to utilise available visual information to predict the future outcome of an event (e.g., position of a ball) and complete a motor response, such as to strike a ball in baseball or cricket batting (Rosalie \& Müller, 2013). Striking sport skills, such as cricket batting, rely heavily upon perceptual-motor anticipation due to the high temporal constraint of ball velocity that leaves little time for the batsman (performer) to read the bowler's (opponent) kinematics and ball flight to make effective bat-ball interception (Müller \& Abernethy, 2012).

Previous sport expertise studies in striking sports indicate that a group of highly skilled performers possess a superior capability compared with a group of less skilled players. In particular, highly skilled performers have superior capability to perceive visual information from an opponent's movement pattern prior to object flight (known as advance information) and parts of ball flight to anticipate subsequent events, such as the type of tennis serve (e.g., Shim, Carlton, Chow, \& Chae, 2005). In relation to cricket batting, which is the exemplar striking sport skill of this study, temporal occlusion in situ method has been used where the performer's vision is occluded at select times in the opponent's movement pattern or during ball flight using special liquid crystal glasses worn by the performer. These types of studies have indicated how visual information is used to guide component phases of the striking skill. It has been reported that a group of highly skilled cricket batsmen, but not a group of less skilled players, use advance and early ball flight information to anticipate ball length (or ball landing position) and position their lower body for batball interception (Müller et al., 2009). This is determined by foot movements made forward to balls that land closer to the batsman and backward foot movements to balls that land further away from the batsman (Müller et al., 2009). Highly skilled batsmen also use ball flight information prior to ball bounce to anticipate and intercept (strike) a delivered ball (Müller et al., 2009). Other studies by Hubbard and Seng (1954) used chronometric analysis, which involves quantifying timing and sequencing of motor execution relative to key events in an opponent's movement pattern. The authors reported that a group of major league baseball batters facing pitchers initiated their stride in the batting motion at the moment the pitcher released the ball, signifying the batters utilised early visual information to guide lower body positioning. Bat downswing was commenced before the step was concluded with the length of time of the downswing remaining uniform (Hubbard \& Seng, 1954). Initiation of bat downswing prior to completion of the front-foot stride also has been reported in cricket batting (Stuelcken, Portus, \& Mason, 2005). Recently, Weissensteiner, Abernethy, and Farrow (2011) used a bowling machine and reported that a group of highly skilled cricket batsmen initiated and completed their front-foot movement earlier than a group of less skilled players. The authors also reported that bat downswing of highly skilled players was initiated after front-foot landing, whilst bat downswing of less skilled players was initiated before front-foot landing. Therefore, the foregoing studies demonstrate that a model of expert striking skill includes the capability to use earlier visual information to guide action, but the coordination pattern of action can vary dependent upon whether an opponent is present or not.

The field of sport biomechanics also has an interest in expert sport performance with focus upon motor skill execution, rather than the contribution of visual-perception to action. For example, Katsumata (2007) tested a group of college baseball batters batting against a pitching machine whilst standing on force plates, which were used to measure their completion of weight transfer as they attempted to hit pitches. The author reported that the group of batters were able to identify differences in pitch velocities, as implied by the variations in the timing of weight transfer completion and step duration that were identified, particularly in relation to slower velocity pitches. Another example study, Fortenbaugh, Fleisig, OnarThomas, and Asfour (2011) supported these findings when they reported that a group of double-A Minor League baseball batters showed variations in the timing of weight transfer completion dependent upon the velocity of the pitch. Like the field of sport expertise, these example sport biomechanics studies through their group designs describe one model of motor skill execution in relation to biomechanical variables, rather than investigating whether multiple individual coordination patterns exist. In addition, the foregoing biomechanical studies lack systematic manipulation of visual-perceptual information in their experimental design to determine the linkage between important visual skills of anticipation to guide biomechanical variables of action, such as weight transfer between individual performers.

Little is known about the visual perceptual-motor skill differences between individuals within expert or highly skilled groups in striking sports. This is surprising, because theoretically there are in existence prominent motor control and learning theories that argue for a focused analysis at the level of the individual. Newell's (1986) constraints theory identified that the individual's interaction with the task and immediate environment constrains the coordination pattern to achieve the motor skill goal. Newell's theory forms a key component for dynamical and ecological system theory, which emphasises that the performer (e.g., individual cricket or baseball batsman), environment, and action linkages are the most appropriate for the understanding of visual perceptual-motor behaviour, not the performer or the environment studied in isolation or necessarily in groups (Davids, Button, \& Bennett, 2008; Uehara, Button, Falcous, \& Davids, 2014). It is argued that constant communication between the performer (individual) and the environment provides the most important perceptual information to guide motor skill performance and learning 
(Davids et al., 2008; Uehara et al., 2014). Factors including visual-perceptual, biomechanical, emotional and psychological characteristics, as well as specific task constraints are all argued to have a facilitory or limiting effect on the motor skill of the performer-environment system (Davids et al., 2008). In relation to the study in this paper, cricket batsmen, like performers in other striking sports, have to individually overcome key task constraints, such as higher object velocity and coordinate their striking pattern when facing fast bowlers to strike a fast approaching ball. Therefore, understanding how individuals use visual-perceptual information to guide biomechanical variables of action under time constraints has the potential to extend theoretical understanding of expertise in striking sports.

There are fewer studies that focus their comparisons between individual performers in terms of complex whole body visual perceptual-motor skills. For example, Dicks, Davids, and Button (2010) examined individual differences in a visual anticipation task where experienced association football goalkeepers attempted to intercept penalty kicks. Results showed variation in response time with some goalkeeper's initiating their response earlier and others later. The authors also reported descriptive individual differences in the percentage of goals saved. More recently, in an attempt to move towards individual differences in the use of visual-perception to guide biomechanical action variables, Müller, Lalović, Dempsey, Rosalie, and Harbaugh (2014) conducted some preliminary research using in situ temporal occlusion (visual-perception) with measures of weight transfer and bat movements (action variables). Baseball batters faced pitchers and attempted to intercept pitched balls whilst their vision was occluded during mid ball flight. In relation to swings at pitches, the authors reported that a Major League Baseball (MLB) batter completed his weight transfer significantly earlier than the collective group of five Australian Baseball League (ABL) batters, with initiation of bat downswing of the MLB batter earlier than some ABL batters, but there was no difference in duration of bat downswing. The MLB batter also attained a higher percentage of successful hits than the collective group of ABL batters. In baseball batting, at least, it appears that early visual information is used to time earlier completion of weight transfer and to some degree earlier bat downswing initiation. Further research is required to expand upon these preliminary findings with comparisons between individual performers.

To provide an explanation of how performers cope with constraints, Müller and Abernethy (2012) reviewed the literature and provided a model of expertise in striking sports. Their model outlines that experts are capable of using different types of visual-perceptual information that are linked to component phases of the striking action. For example, as mentioned earlier, advance and part of ball flight information is used to guide lower body movements (weight transfer) in baseball or cricket batting, whilst ball flight information is used to guide upper body (bat) movements. Their model also outlines that less skilled performers use different and relatively later occurring visual-perceptual information to guide component phases of action (body positioning and bat movements). The authors argue that these differences in the linkage of perceptual information to action are what enable expert performers to deal with high temporal constraints of object flight and respond efficiently to achieve successful bat-ball interception. The authors also argue that under temporal constraints of object velocity it may only be possible for the performer to make adjustments to the striking implement, but not the lower body phase of the skill. What is less evident from their model is whether there are individual differences amongst experts in the use of visual information to time action.

Further evidence from coordination patterns exists of how performers cope with performance constraints in striking skills. Whilst skilled actions exhibit some stable characteristics, it also is apparent that skilled performers are not locked into rigidly stable solutions (coordination patterns), but can modulate their behaviours to achieve consistent performance outcome goals. For example, Pinder, Davids, and Renshaw (2012) studied the perceptual-motor coordination pattern of skilled cricket batsmen and found that when the length of delivery (ball landing position) was altered to require the batsmen to make a decision regarding the length of the ball they faced, various movement patterns were observed when the batsmen attempted to strike the ball. This observation of the flexibility and adaptability of visual perceptual-motor skill coordination is closely linked to the concept of motor equivalence, which refers to the equality of motor skill outcome or goal achievement from different movement patterns or muscle contractions (Mattos, Latash, Park, Kuhl, \& Scholz, 2011; Mattos, Kuhl, Scholz, \& Latash, 2013). Investigation of individual differences may explain whether different perceptualmotor coordination patterns can be used to achieve a similar goal of bat-ball interception in complex whole body striking skills.

The purpose of this in-situ study was to combine methodologies from sport expertise and sport biomechanics in an attempt to gather information about individual differences in the pick-up of visual information (perception) to time weight transfer and bat movements (coordination) within a group of expert cricket batsmen. This study used highly skilled cricket batsmen (as the exemplar striking skill experts) to examine the timing of weight transfer together with bat kinematics (action variables) within an in situ temporal occlusion task (perception). Accordingly, this study involved a between-subject design with individual batsmen compared to each other separately on four biomechanical variables. An in situ temporal occlusion paradigm was used to challenge each batsman's capability to use advance and ball flight information prior to ball bounce to coordinate their movement pattern to strike delivered balls, based upon previous research (Müller et al., 2009; 
Müller et al., 2014). Due to the lack of previous studies that have investigated individual differences of experts in striking sports, it was hypothesised that: 1) there may be some individual differences in the pick-up of early visual-perceptual information to time action variables between highly skilled cricket batsmen, and 2) there may be descriptive differences in measures of bat-ball interception between highly skilled cricket batsmen.

\section{Methods}

\section{Participants}

Eight highly skilled cricket batsmen, six right-handed and two left-handed $\left(M_{\mathrm{age}}=21.33\right.$ years, age range 18-27 years), from a state high performance squad in Australia were recruited to take part in this study. The batsmen were a representative sample taken from 12 batsmen and comprised $75 \%$ of the highly skilled batting population in the region the study was conducted. Compared with previous in situ studies, the sample of this experiment equates very positively (Dicks et al., 2010; Müller \& Abernethy, 2006). Four right-handed fast bowlers from the same high-performance state squad also were recruited to bowl to the batsmen throughout the testing sessions like previous research (Müller et al., 2009). Ethics approval was obtained from the relevant institution, and all participants provided written, informed consent.

\section{Instruments}

This study was conducted in a performance laboratory. The laboratory included a full-length cricket pitch $(20.12 \mathrm{~m})$ surrounded in part by an indoor batting cage, with a halflength synthetic cricket pitch on the surface of the laboratory floor to provide similar conditions as a synthetic cricket wicket often utilised for indoor and outdoor cricket practice. An adequate area was available behind the full-length pitch to allow the bowlers sufficient space for bowling run-up. A Qualysis Motion Capture System that synchronised two high-speed cameras (sampling at 200 frames per second) with two Kistler force plates, $0.90 \mathrm{~m} \times 0.60 \mathrm{~m}$ (sampling at $2000 \mathrm{~Hz}$ ), was used to measure the force-time data (i.e., initiation and completion of weight transfer). Camera 1 was positioned behind and slightly to the side of the batsman. The footage from this camera captured the bowler's approach, ball release, and all ball flight, together with the crucial information of the time within the ball's flight at which occlusion of vision occurred indicated by illumination of a light emitting diode (LED) in the camera's field of view. Camera 2 was positioned perpendicular to the batsman's bat to capture the movement pattern of the batsman. Vision occlusion glasses (PLATO, Model P1, Translucent Technologies Inc., Toronto,
Ontario, Canada) worn by the batsman were manually triggered by a handheld wireless remote controller to switch the glasses from clear (where the batsman had visibility of the bowler's action and ball flight) to opaque (where the batsman had no visibility of the bowler's action and ball flight) during occlusion trials, according to previous research (Müller et al., 2009). The process involved two wireless receivers accepting an ultra-high-frequency (UHF) signal emitted by a UHF transmitter contained within the wireless handheld controller. The signal sent to receiver one turned on an LED contained in the field view of high-speed camera 1 . The LED in this camera's field of view indicated the instant when during ball flight the batsman's vision was occluded. The second receiver, housed in a waist belt attached around the waist of the batsman, triggered the conversion of the lenses in the occlusion glasses from clear to opaque. Due to the difficulties associated with manual triggering of occlusion at certain events, prior to the experiment proper, the bowlers were filmed in high-speed (250 frames per second) from side-on and the time between back-foot landing and ball release was calculated for each bowler. Then, the time from back-foot landing to ball release (relative to each bowler) plus $200 \mathrm{~ms}$ was factored into the remote controller to attempt to create occlusion of the batsman's vision prior to ball bounce. A standard $25-\mathrm{Hz}$ video camera filmed each participant's trials from front-on to assist with quality of bat-ball interception reliability check.

\section{Procedures}

The procedures were similar to those implemented in previous research (Müller et al., 2009). Each testing session took approximately 1.15 hours per batsman where each batsman faced the same four bowlers. Before the testing began, each batsman prepared themselves for a batting session with standard cricket protective equipment, that is, they wore leg guards, protector, thigh guard, batting gloves, and a compulsory batting helmet for protection of the batsman's face and occlusion glasses. After the force plates were calibrated, the batsman stood on the plates in their normal batting stance, ensuring that only one foot was located on each force plate. The batsman was instructed to utilise the gap in-between the force plates as the batting crease. In order to familiarise the batsman with the experimental conditions, each batsman received ten deliveries with random occlusion or no occlusion conditions. After familiarisation, the experiment proper began and each batsman faced a total of 60 deliveries in random order composed of three ball types $\mathrm{x}$ two temporal occlusion conditions $\mathrm{x}$ ten repeats. The bowlers delivered three types of balls: (a) full-length outswinger (ball lands closer to the batsman and swings to the right side), (b) full-length inswinger (ball lands closer to the batsman and swings to the left), and (c) short ball (ball lands further away from the batsman and bounces higher). Short-length balls landed at least $4 \mathrm{~m}$ away 
from the batsman's stance position on the force plates, whilst full-length balls landed within $4 \mathrm{~m}$ of the batsman's stance position. Two temporal occlusion conditions were created: (i) vision of bowler's action (advance information) and ball flight till a point prior to ball bounce and (ii) a no occlusion control condition where all advance and ball flight information was visible to the batsman. The batsmen faced the required ball types and occlusion condition matrix in a fully randomised order. On each trial, the experimenter who stood at the bowler's end of the pitch indicated to the bowler what ball type to deliver, and then, during the trial either triggered the glasses to occlude vision or did not trigger the glasses (no occlusion). The highly skilled bowlers were capable of executing the required ball types accurately. Upon completion of each trial the experimenter rated on a data sheet the quality of bat-ball contact (see below).

\section{Dependent measures}

In the occlusion condition, trials were post-hoc sorted using a frame-by-frame analysis of the high-speed video record to ensure temporal occlusion had been created prior to ball bounce as done in previous research (Müller et al., 2009). As ball flight information leading towards ball bounce had been previously reported to be a critical point for use of visual information to strike a ball in cricket batting (Müller et al., 2009), only those trials in a close grouping within a range of $200 \mathrm{~ms}$ prior to ball bounce were included in the analysis in the occlusion condition. This was done to minimise the variability in occlusion point from the time of ball bounce between participants. From this post-hoc sorting, equal numbers of trials for each individual batsman were derived for the occlusion and no-occlusion conditions to provide balanced proportions, but length of the balls were collapsed together for statistical analysis. More trials occurred under the no occlusion condition, so no occlusion trials were selected in order of their first appearance in the random matrix until each batter had an equal number of occlusion and no occlusion trials. The grouping of full and short deliveries together for analysis was done to ensure a decision-making element (i.e., judgement to coordinate movement pattern to strike) was factored into study design and analysis.

The primary dependent variables in this study (kinetics and kinematics) included: (i) weight transfer initiation, (ii) weight transfer completion, (iii) bat downswing initiation, and (iv) bat downswing completion, all from the time of ball release. To obtain values for weight transfer initiation and completion, the final definitive foot movement for batting strokes made forward (i.e., movement of the lower body forward using frontfoot to balls that landed closer to the batsman) and backward (i.e., movement of the lower body backward using back-foot to balls that landed further from the batsman) were analysed according to previous literature (Abernethy, 1984). A separate dependent measure of bat-ball interception was recorded, that is, a rating of quality of bat-ball contact.

The kinetic and kinematic dependent variables were defined as: (i) weight transfer initiation, the time point from ball release where the front-foot vertical ground reaction force was equal to or at zero and when the corresponding back foot anterior-posterior force increased from a stable baseline value, indicating the push forward for a front-foot stroke (Elliott, Baker, \& Foster, 1993). This definition is reversed for backfoot strokes. (ii) Weight transfer completion, the time point from ball release of the peak vertical ground reaction force on the front-foot (Katsumata, 2007). For back-foot strokes this would be peak vertical ground reaction force on the back-foot. (iii) Bat downswing initiation, the time point from ball release when the bat begins to move in a direction towards interception of the ball (Weissensteiner et al., 2011). (iv) Bat downswing completion, the time point from ball release till bat-ball interception or where the ball was adjacent to the edge of the bat (Weissensteiner et al., 2011).

The rating of bat-ball interception was conducted "live" and defined as: (a) "good" bat-ball contact (i.e., ball struck in direction bat was swung), (b) "bad" bat-ball contact (i.e., ball struck in a different direction bat was swung), and (c) "no" bat-ball contact, according to Müller and Abernethy (2008). A research assistant not involved in the study viewed the front-on video camera footage of all trials in the occlusion condition and rated quality of bat-ball interception to establish interrater reliability (Müller \& Abernethy, 2008). An approximation of average speed of the delivered balls was calculated by viewing footage from the high-speed camera and applying the formula speed $(\mathrm{m} / \mathrm{s})=$ distance from the point of ball release to the batsman's stance position $(17.72 \mathrm{~m})$, divided by the ball transit time from the time of ball release until the instant of bat-ball contact or where the ball passed the edge of the bat if contact was unsuccessful (in ms), and then converted into $\mathrm{km} / \mathrm{h}$, according to the literature (Müller et al., 2009).

\section{Statistical analysis}

The primary dependent variables in this study were initiation and completion of weight transfer, bat downswing initiation and bat downswing completion. These variables are ratio scale so they were analysed on an individual trial basis for each participant using parametric tests (Land \& McLeod, 2000). The secondary dependent variable was quality of bat-ball contacts. This variable is a categorical scale so a nonparametric test was appropriate (Field, 2009). A series of statistical tests were conducted as follows. First, a chi-square test was run to determine if there was a significant difference in the frequency of full- and short-length deliveries relative to each participant. Second, an 8 (participant) $\times 2$ (occlusion condition) between factor ANOVA was run to determine if there was a significant difference in average speed between individual participants 
and across occlusion conditions. This was done to determine whether speed had been kept within a similar range for each batsman and if not whether covariate analysis was required when analysing the primary dependent variables. Third, a oneway ANOVA was run to determine if there was a significant difference between participants in occlusion time prior to ball bounce. Fourth, four separate 8 (participant) $\times 2$ (occlusion condition) between factor ANCOVA with average speed as a covariate were run to determine whether there were differences in timing of each of the primary dependent variables across the occlusion conditions relative to individual participants. This statistical analysis helped justify whether betweensubject comparisons of the primary dependent measures could be focused upon the occlusion condition only, if there was no difference in the timing variables across occlusion conditions. Focus of the subsequent analysis upon the occlusion trials was because previous research had reported the importance of the use of advance information and ball flight information prior to ball bounce to guide positioning of the lower body as well as the bat for interception, respectively. Fifth, a MANCOVA was run combining all dependent variables with participant as a between factor and average speed as a covariate. This was done to determine whether participant factor was influencing timing differences on each dependent variable. As appropriate based on the results of the MANOVA omnibus test, four separate follow-up univariate ANCOVA with average speed as the covariate were then run to compare each of the timing variables independently between participants in the occlusion condition, with least significant difference (LSD) post-hoc pairwise comparisons. For the secondary dependent measure, a chi-square test was used to compare frequencies of quality of bat-ball contacts that were five or above based upon guidelines by Field (2009), in groupings of "good" and "bad" ("all") bat-ball contacts to "no" bat-ball contacts between participants in the occlusion condition. Groupings of all contacts to no contacts provided an indication of positioning of the bat for interception based upon the use of ball flight information prior to ball bounce (Müller et al., 2009). The purpose of comparing the frequencies of these grouping between participants was to determine whether there were individual differences in the achievement of the outcome goal of positioning the bat for interception. Interrater reliability of rating quality of bat-ball contacts was calculated by using intraclass correlation according to Portney and Watkins (2009). Because the methodology of this study was a first of its kind in terms of individual participant comparisons, alpha level was set at 0.05 with no adjustments made for any post hoc pairwise comparisons (Perneger, 1998). All assumptions in relation to the parametric and nonparametric statistical tests were checked and not violated, according to the procedures outlined by Field (2009).

\section{Results}

Experimental manipulation checks

Table 1 outlines descriptive data for average speed, trial numbers under occlusion and no occlusion conditions for full and short length deliveries, as well as occlusion time prior to ball bounce. Chi-square test revealed there was no significant difference in the frequency of fulland short-length deliveries across participants, $\chi^{2}(7)=$ $7.02, p=0.426$.

Speed Between factor ANOVA revealed a significant main effect for participant, $F(7,238)=12.49, p<$ $0.001, \eta_{\mathrm{p}}{ }^{2}=0.26$, indicating that average speed was significantly different between individual participants. There was, however, no significant main effect for occlusion, $F(7,238)=0.02, p=0.888, \eta_{\mathrm{p}}^{2}=0.00$, nor a significant interaction between participant and occlusion condition, $F(7,238)=0.45, p=0.868, \eta_{\mathrm{p}}{ }^{2}=0.01$, indicating that average speed did not vary across occlusion conditions relative to individual participants. This finding required the treatment of average speed as a covariate in future analyses under the occlusion condition for each dependent variable.

Table 1 Average speed, trial numbers and occlusion time relative to participant

\begin{tabular}{|c|c|c|c|c|c|}
\hline \multirow[t]{2}{*}{ Participants } & \multicolumn{2}{|c|}{ Speed (kph) } & \multicolumn{2}{|c|}{ Trial Numbers } & \multirow{2}{*}{$\begin{array}{l}\text { Occlusion } \\
\text { time (ms) } \\
M(\mathrm{SD})\end{array}$} \\
\hline & $\begin{array}{l}\text { Occlusion } \\
M \text { (SD) }\end{array}$ & $\begin{array}{l}\text { No } \\
\text { occlusion } \\
M(\mathrm{SD})\end{array}$ & $\begin{array}{l}\text { Occlusion } \\
\text { (Full, } \\
\text { Short) }\end{array}$ & $\begin{array}{l}\text { No } \\
\text { occlusion } \\
\text { (Full, } \\
\text { Short) }\end{array}$ & \\
\hline 1 & $\begin{array}{c}109.62 \\
\quad(5.50)\end{array}$ & $\begin{array}{r}109.25 \\
(6.40)\end{array}$ & $\begin{array}{l}16 \\
(9,7)\end{array}$ & $\begin{array}{l}16 \\
\quad(9,7)\end{array}$ & $\begin{array}{l}96.87 \\
\quad(45.38)\end{array}$ \\
\hline 2 & $\begin{array}{r}109.00 \\
(9.23)\end{array}$ & $\begin{array}{r}108.80 \\
(5.97)\end{array}$ & ${ }^{15}(5,10)$ & ${ }^{15}(5,10)$ & $\begin{array}{l}70.33 \\
\quad(54.16)\end{array}$ \\
\hline 3 & $\begin{array}{c}110.21 \\
(6.12)\end{array}$ & $\begin{array}{r}109.42 \\
\quad(6.18)\end{array}$ & $\begin{array}{l}19 \\
\quad(12,7)\end{array}$ & $\begin{array}{l}19 \\
\quad(12,7)\end{array}$ & $\begin{array}{l}82.89 \\
\quad(49.95)\end{array}$ \\
\hline 4 & $\begin{array}{r}102.21 \\
(6.65)\end{array}$ & $\begin{array}{l}100.00 \\
(6.64)\end{array}$ & $\begin{array}{l}14 \\
(5,9)\end{array}$ & $\begin{array}{l}14 \\
(5,9)\end{array}$ & $\begin{array}{l}88.92 \\
\quad(58.87)\end{array}$ \\
\hline 5 & $\begin{array}{c}100.79 \\
(5.61)\end{array}$ & $\begin{array}{r}100.86 \\
(4.88)\end{array}$ & ${ }^{14}(5,9)$ & ${ }^{14}(5,9)$ & $\begin{array}{l}68.93 \\
\quad(57.92)\end{array}$ \\
\hline 6 & $\begin{array}{l}99.53 \\
\quad(9.44)\end{array}$ & $\begin{array}{r}103.30 \\
(7.06)\end{array}$ & $\begin{array}{l}13 \\
\quad(5,8)\end{array}$ & $\begin{array}{l}13 \\
\quad(5,8)\end{array}$ & $\begin{array}{l}79.23 \\
\quad(58.20)\end{array}$ \\
\hline 7 & $\begin{array}{c}101.00 \\
\quad(6.20)\end{array}$ & $\begin{array}{r}101.55 \\
(5.74)\end{array}$ & $\begin{array}{l}20 \\
\quad(10,10)\end{array}$ & $\begin{array}{l}20 \\
\quad(10,10)\end{array}$ & $\begin{array}{l}88.75 \\
\quad(47.12)\end{array}$ \\
\hline 8 & $\begin{array}{c}105.68 \\
(7.12)\end{array}$ & $\begin{array}{r}105.81 \\
(5.94)\end{array}$ & $\begin{array}{l}16 \\
(10,6)\end{array}$ & $\begin{array}{l}16 \\
(10,6)\end{array}$ & $\begin{array}{l}95.93 \\
\quad(64.53)\end{array}$ \\
\hline
\end{tabular}

Occlusion time is prior to ball bounce. Full refers to full-length balls that landed closer to the batsman, and short refers to short-length balls that landed farther away from the batsman 
Occlusion time One-way ANOVA revealed no significant difference in occlusion time prior to ball bounce between participants, $F(7,119)=0.581, p=0.770$, indicating that post hoc sorting of occlusion trials prior to ball bounce was successful.

Participants, occlusion conditions, and timing variables Between factor ANCOVA revealed that there was no significant interaction between participant and occlusion condition for each of the timing measures: weight transfer initiation, $F(7,237)=1.13, p=0.339, \eta_{\mathrm{p}}{ }^{2}=0.03$; weight transfer completion, $F(7,237)=0.598, p=0.757$, $\eta_{\mathrm{p}}{ }^{2}=0.01$; bat downswing initiation, $F(7,237)=0.745, p$ $=0.634, \eta_{\mathrm{p}}{ }^{2}=0.02$; and bat downswing completion, $F(7$, $237)=0.14, p=0.859, \eta_{\mathrm{p}}{ }^{2}=0.01$. There also was no significant main effect for occlusion conditions for each of the timing measures ( $p \mathrm{~s}>0.05$ ). There was, however, significant main effects for participant in relation to each of the timing measures: weight transfer initiation, $F(7$, $237)=6.19, p<0.001, \eta_{\mathrm{p}}^{2}=0.15$; weight transfer completion, $F(7,237)=2.27, p=0.029, \eta_{\mathrm{p}}{ }^{2}=0.06$; bat downswing initiation, $F(7,237)=16.50, p<0.001, \eta_{\mathrm{p}}{ }^{2}$ $=0.32$; and bat downswing completion, $F(7,237)=8.12$, $p<0.001, \eta_{\mathrm{p}}{ }^{2}=0.19$. Therefore, because the timing measures for participants did not differ significantly across occlusion conditions, further comparison of the timing measures between participants was focused on the occlusion condition only.

Kinetic and kinematic timing variables

MANCOVA revealed a significant main effect for participant, $\Lambda=0.38, F(28,416)=4.47, p<0.001, \eta_{\mathrm{p}}{ }^{2}=0.21$. Follow-up ANCOVA were then conducted on each of the dependent timing variables.

Weight transfer initiation Figure 1a graphs the mean weight transfer initiation time relative to each participant expressed from earliest to latest values. ANCOVA indicated a significant between participant effect, $F(7$, $118)=5.16, p<0.001, \eta_{\mathrm{p}}{ }^{2}=0.23$, confirming there was a difference in mean weight transfer initiation time between participants. Post hoc LSD pairwise comparisons indicated that participant 8 was different than all other participants and participant 7 was different than participant $4(p s<0.05)$.

Weight transfer completion Figure $1 \mathrm{~b}$ graphs mean weight transfer completion relative to each participant. ANCOVA indicated no significant between participant effect, $F(7$, $118)=1.39, p=0.214, \eta_{\mathrm{p}}{ }^{2}=0.07$, confirming there was no significant difference between participants in mean weight transfer completion time.

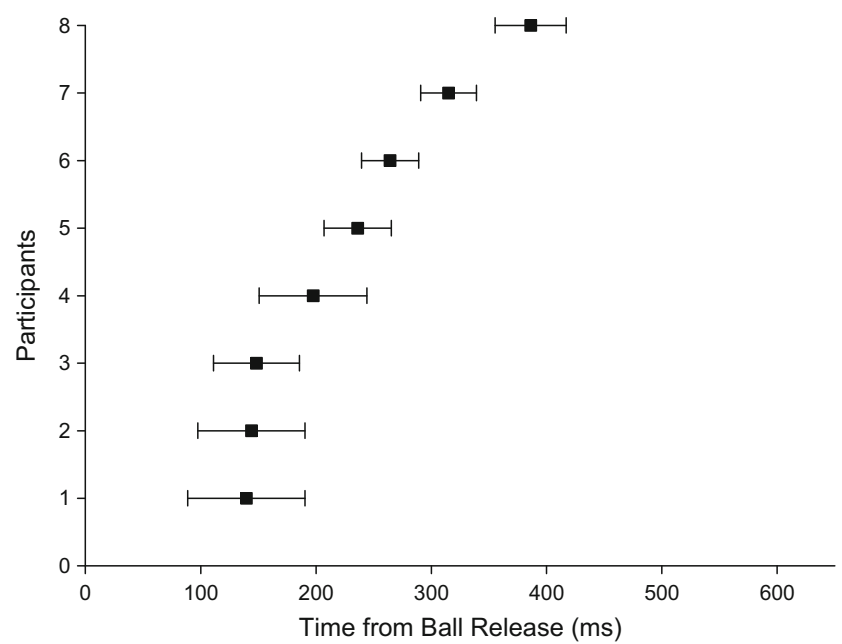

(a)

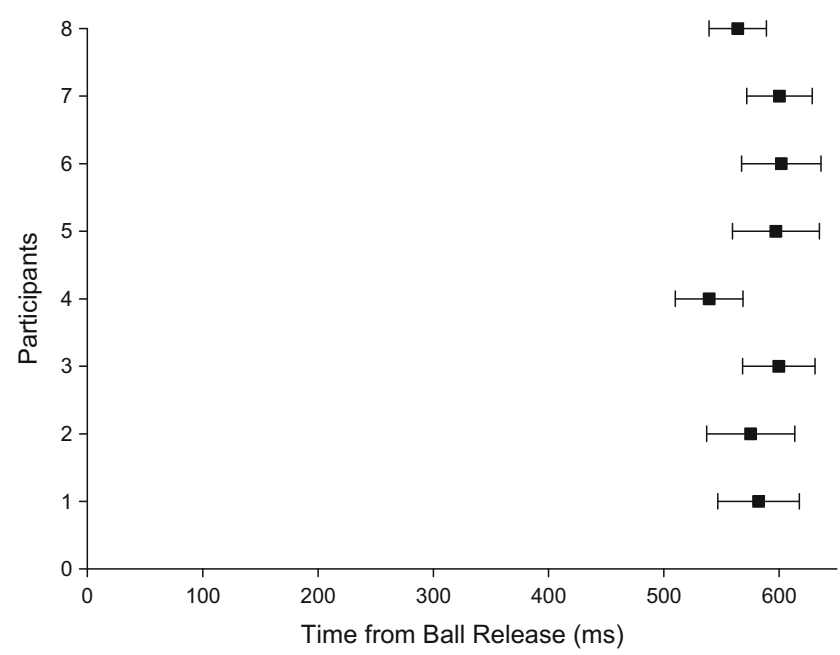

(b)

Fig. 1 Mean weight transfer initiation time (ms) (a) and mean weight transfer completion time (ms) (b) for each participant. Participant timing values are plotted from earliest to latest for (a) with participant number corresponding for (b). Error bars represent standard error of the mean

Bat downswing initiation Figure 2a graphs mean downswing initiation time relative to participants. ANCOVA indicated a significant between participant effect, $F(7,118)=8.36, p<$ $0.001, \eta_{\mathrm{p}}{ }^{2}=0.33$, confirming there was a difference in mean bat downswing initiation time between participants. Post hoc LSD pairwise comparisons indicated that participant 7 was different than all other participants, participant 6 was different than participants 5 and 7 , and participant 5 was different than participants 6,3 , and $2(p s<0.05)$.

Bat downswing completion Figure $2 \mathrm{~b}$ graphs mean downswing duration time relative to participant. ANCOVA indicated a significant between participant effect, $F(7$, 118) $=2.75, p=0.01, \eta_{\mathrm{p}}{ }^{2}=0.14$, confirming there was a difference in mean bat downswing completion 


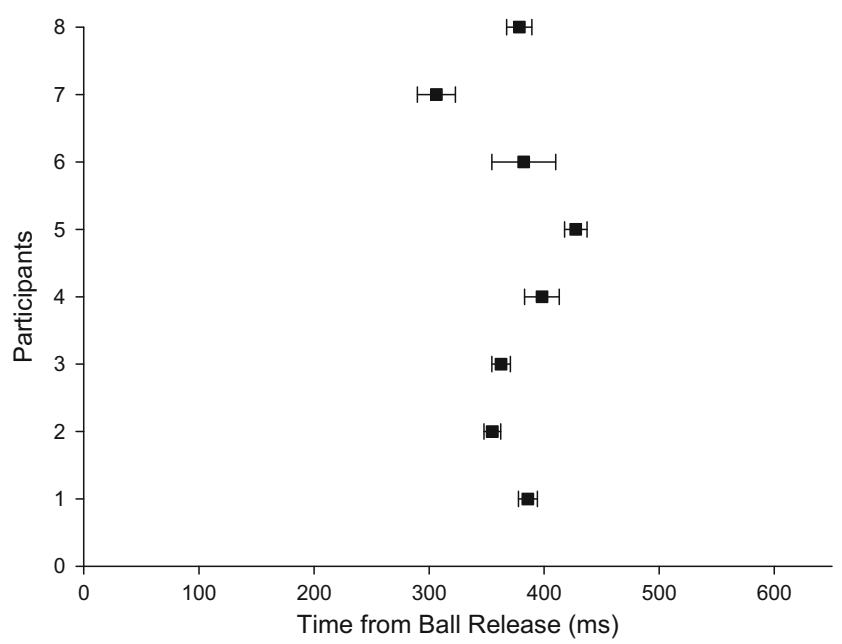

(a)

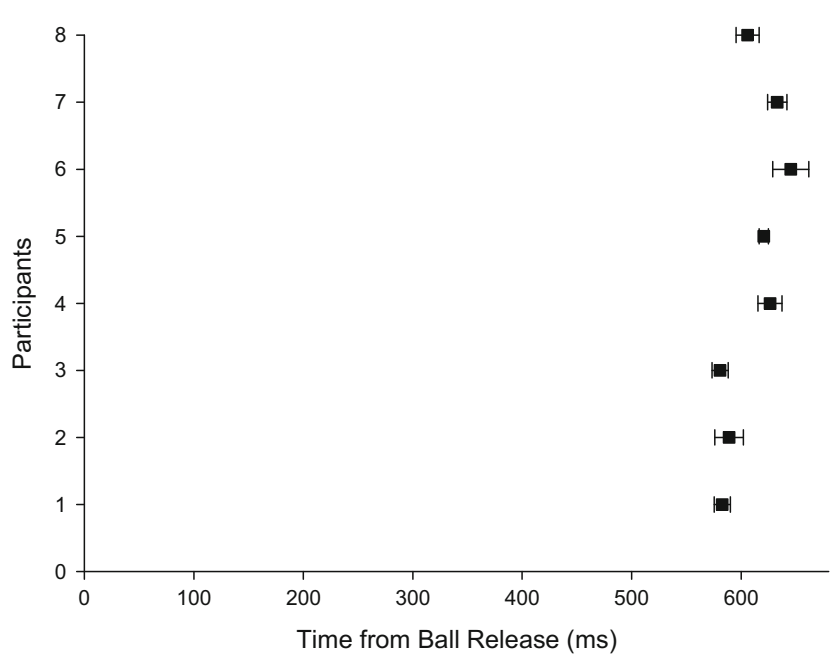

(b)

Fig. 2 Mean bat downswing initiation time (ms) (a) and mean bat downswing completion time (ms) (b) for each participant. Timing values are plotted to correspond with participant number in Fig. 1 (a) and (b). Error bars represent standard error of the mean

time between participants. Post hoc LSD pairwise comparisons indicated that participant 5 was different than all other participants $(p s<0.05)$.

Quality of bat-ball contacts

Figure 3 graphs the descriptive frequency data for each participants" "all" bat-ball contacts against the frequency for "no" bat-ball contacts. Pearson chi-square test indicated there was no significant difference in the frequency of bat-ball contacts between participants, $\chi^{2}(7)=$ $3.247, p=0.861$. Intraclass correlation revealed strong interrater reliability between "live" rating of bat-ball contacts and rating of the same trial from the video record $(r=0.96)$.

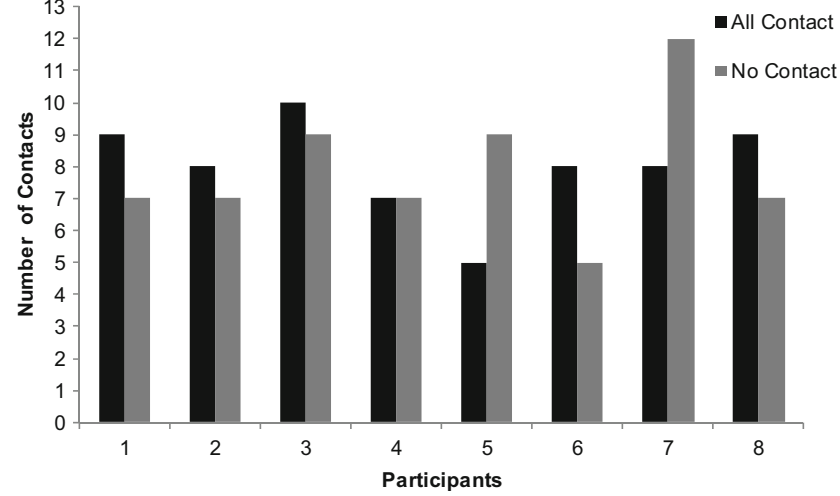

Fig. 3 Total frequency of "all" bat-ball contacts versus "no" bat-ball contacts for each participant. Frequency of contacts are plotted to correspond with participant number in Figs. 1 and 2

\section{Discussion}

The purpose of this study was to unite approaches used by researchers in the fields of sport expertise and sport biomechanics in an attempt to gather information about individual differences in the pick-up of visual information to time weight transfer (kinetics) and bat movement (kinematics) within a group of highly skilled cricket batsmen. The study was conducted under experimental conditions where a performer and opponent competed against each other in order to simulate to a degree the interaction between the two that occurs in a game setting. The results support hypothesis one indicating that individual differences do exist in the coordination pattern of highly skilled batsmen. The results partially support hypothesis two where descriptive individual differences were found in quality of bat-ball contacts between highly skilled batsmen, but analyses indicated no statistically significant descriptive differences.

Based on the chronometric analysis, some of the highly skilled cricket batsmen appeared to utilise available visual information within the temporal occlusion condition to anticipate and time weight transfer initiation significantly earlier, whilst others initiated weight transfer significantly later (Fig. 1a). This indicates there were some individual preferences of how visual-perceptual information is used to time kinetics within a group of highly skilled cricket batsmen. Similarly, significant differences were found between some batsmen in the use of visual information within the temporal occlusion condition to time earlier and later initiation of bat downswing (Fig. 2a). This again supports the notion of individual differences, but in this case residing in the use of available visual-perceptual information to time kinematics within a highly skilled group. It may well be that some individual batsmen initiated weight transfer and bat downswing as their duration of response was longer and vice versa. Theoretically, these findings are consistent with Newell's (1986) constraints theory, as well as the theoretical framework of ecological and 
dynamical systems theory (Davids et al., 2008; Uehara et al., 2014), which suggests that motor skill performance evolves through the individual that exploits the task and environment constraints to coordinate the body's degrees of freedom to achieve the relevant motor skill goal. This has important implications for models of expertise in striking sports, such as the one recently presented by Müller and Abernethy (2012). In particular, the findings of this study imply that more than one pattern or model exists for the visual control of biomechanical action variables. Given that very few individual difference studies exist in the literature, further research is needed to confirm the findings of this study, which may then warrant refinement of aspects of Müller and Abernethy's model of striking sport expertise to acknowledge the importance of individual differences in the visual control of action.

In terms of the findings of this study compared with previous literature in sport expertise, it is not possible to make direct comparisons as methodologies are different. The findings of this study are consistent with Dicks et al. (2010) who reported that some soccer goalkeepers initiated responses earlier, whilst other goalkeepers initiated responses later when they anticipated in order to save penalty kicks. Accordingly, the findings of this study indicate that one of the conclusions made in the sport expertise literature that experts use early visual information to respond earlier than less skilled players (Müller et al., 2009) may not be applicable when considered in terms of an expert sample's visual perceptual-motor skills. That is, as a group, it appears that highly skilled players respond earlier than a group of less skilled players (Weissensteiner et al., 2011), but as evidenced by the findings of this study there are small-scale differences in earlier and later responses between individual highly skilled players.

These earlier and later responses between highly skilled performers may be relative to the specific striking skill and the component phase of the specific striking skill. In baseball batting, the batter only makes a forward step, which appears to be initiated at the point of ball release (Hubbard \& Seng, 1954), with earlier completion of weight transfer reported for a MLB batter in comparison to ABL batters (Müller et al., 2014). In cricket batting, the batter has to transfer weight both forwards and backwards to strike a ball. There were no significant individual differences, however, in weight transfer completion in this study, with completion of weight transfer occurring after initiation of bat downswing (Fig. 1b and 2a). Again, this finding seems to be at odds with suggestions in the sport expertise literature of earlier positioning of the lower body component of the striking skill to cope with the time constraint of ball velocity and time upper body bat movements for bat-ball interception (Müller \& Abernethy, 2012). This may again be relative to the specific striking skill of this study that required forward and backward body positioning. Alternatively, perhaps the more accurate description should be that experts pick-up early visual information to time earlier initiation of lower body movement (weight transfer initiation) rather than earlier positioning of the lower body (that may imply weight transfer completion). Further research is needed to better understand how individuals use visual-perceptual information to guide biomechanical action variables, which can provide, as done here, a better understanding of how visual-perception and action are tightly coupled in expert striking skill (Müller \& Abernethy, 2012).

Trends in the data of this study also reveal how visual perceptual-motor coupling is individualised in relation to component phases of the striking skill. That is, some batsmen such as participants one and four appeared to initiate their weight transfer earlier (Fig. 1a) but correspondingly coupled later initiation of bat downswing (Fig. 2a). This trend in the data is consistent with studies by Pinder, Renshaw, and Davids (2009) and Stuelcken et al. (2005) who found that batsmen could initiate lower body movements earlier, but delayed downswing of the bat to enable pick-up of any changes in ball flight information. These types of coupling between lower and upper components of the striking skill may be related to the time constraints under which the batting skill is performed. If the lower body component (weight transfer) is initiated earlier, then there is likely time to wait to initiate bat downswing relatively later for effective bat-ball interception (Abernethy, 1981). Although if the lower body component (weight transfer) is initiated later, then the bat downswing will need to be initiated relatively earlier in order for effective bat-ball interception (Abernethy, 1981). Trends in the data (error bars) also indicate that across individual batters there appears to be greater variability in the timing of weight transfer components (Fig. 1a and b) and less variability of the end-point (bat downswing completion; Fig. 2b). This observation is consistent with previous studies of end-point variability in expert samples (Bootsma \& van Wieringen, 1990). Future research that investigates the sequencing and variability of component phases in the striking skills at the individual participant level would further advance understanding of how these skills are performed under high time constraints.

An important and unexpected finding of this study was that no significant difference was found in the frequency of bat-ball contacts between individual batsmen. When this finding is considered in relation to the findings that significant individual differences do exist in some of the action timing measures, it appears that different coordination patterns appear to be used to achieve a similar motor skill goal, that is, in terms of frequency of bat-ball contacts to "no" contacts. Although there were clear descriptive frequency differences in bat-ball contacts between participants, which is consistent with previous literature (Dicks et al., 2010), these descriptive differences were not statistically significant (our analysis for bat-ball contacts did not include speed as a covariate which may influence this finding). This finding implies that motor equivalence may be an underlying mechanism of visual control of action in expert striking skills, which has been reported for 
other motor skill tasks, such as reaching towards a target (Mattos et al., 2011). Anecdotally, it is apparent from observing different sport performers that their exists multiple movement patterns to achieve the relevant motor skill goal, but again, further investigation is required possibly using the methodology in this study to determine if motor equivalence is a consistent underlying mechanism of expertise in striking sports.

Another interesting but unexpected finding of this study was that there was no adjustment to the timing measures across the occlusion conditions. The timing of measures related to lower body movement (weight transfer) did not change significantly from the occlusion condition that provided early ball flight information to the no occlusion condition that provided late ball flight information. This is consistent with the predictions of Müller and Abernethy (2012) model. The timing measures related to upper body movement (bat movements), however, also did not change significantly from the occlusion condition to the no occlusion condition. This appears to be inconsistent with the predictions of Müller and Abernethy (2012) model. These findings imply that under temporal constraints, at least, that the discrete timing of upper and lower body coordination patterns are not continuously adjusted. It may be that whilst discrete timing of component phases of the skill are not continuously adjusted, fine positioning of the bat may be adjusted to allow efficient bat-ball interception. This requires further investigation using threedimensional motion capture analysis of lower and upper body striking phases.

The findings of this study can be generalised to understanding expertise in other visual perceptual-motor skills. In relation to the example motor skills, such as laparoscopic surgery, driving, piloting, and law enforcement presented at the beginning of this paper, the finding of this study would predict that there would be significant differences between experts in these domains in terms of how they coordinate perceptual-motor skill to achieve task specific goals. Reinvestigation of the expert individuals within those domains may provide insights into their visual perceptual-motor skills that were not previously known, which can then guide an evidence-based perceptual-motor learning programs. For example, in a recent paper that investigated the kinematics of individual professional and semi-professional flute players, in was reported that finger timing (larger and smaller movements) could identify individual expert performers (Albrecht, Janssen, Quarz, Newell, \& Schöllhorn, 2014). This was contrary to the wellheld belief that expert flute playing required smaller movements of the fingers for efficiency of effort (Albrecht et al., 2014). Individual differences also have been reported in the coordination patterns of other motor skills, such as walking gait (Schöllhorn, Nigg, Stefanyshyn, \& Liu, 2002), which is performed under very different temporal constraints to the striking skill investigated in this paper. Very little empirical evidence exists, however, of individual differences in the visual control of action in high-speed striking sports, as well as other sport skills. The findings of this study support the foregoing studies by indicating that there is more than one coordination pattern to achieve the motor skill goal. The broader understanding of individual differences across a variety of motor skills will help to consolidate motor control and learning theories that emphasise the individual's interaction with task and environment.

In terms of practical application, quantification of individual differences in the pick-up of visual information to guide weight transfer (kinetics) and bat movement (kinematics) can be very useful to the athlete and high-performance coaches. For example, analysis like the one conducted in this study may highlight individual capabilities and deficiencies of one performer compared with others, with the information then used to design individualised coaching and development programs to enhance or remediate motor skill performance. In the case of striking skills, such as baseball or cricket batting, this information may help to answer questions around attainment of, but not limited to, individual batting averages for expert batsmen. Individualised measures of performance as used in this study are critical as performers invest significant time into skill development and improvement.

\section{Conclusions}

Individual differences in the use of visual-perceptual information to coordinate timing of weight transfer and bat movements exist between exemplar individual highly skilled striking sport performers. Whilst different coordination patterns appear to be used, attainment of frequency of bat-ball contacts was not significantly different between individual highly skilled batsmen. This indicates that motor equivalence may be an underlying control mechanism of complex wholebody striking skills, such as cricket batting. Integration of sport expertise and sport biomechanics methods appears necessary to understand these subtle individual differences that exist within a group of highly skilled or expert performers. Further studies are required to confirm the findings of this study with the skill of cricket batting and/or other striking sport skills. This appears to be a fruitful avenue of research to extend theoretical understanding of expertise and practical value for individualised athlete development.

\section{References}

Abernethy, B. (1981). Mechanisms of skill in cricket batting. Australian Journal of Sports Medicine, 13, 3-10.

Abernethy, B. (1984). Skill in cricket batting: Laboratory and applied evidence. In M. L. Howell \& B. D. Wilson (Eds.), Proceedings of 
the VII Commonwealth and International Conference on Sport, Physical Education, Recreation and Dance (Vol. 7, pp. 35-50). Brisbane, Australia: University of Queensland.

Albrecht, S., Janssen, D., Quarz, E., Newell, K. M., \& Schöllhorn, W. I. (2014). Individuality of movements in music - Finger and body movements during playing of the flute. Human Movement Science, 35, 131-144. doi:10.1016/j.humov.2014.03.010

Bootsma, R. J., \& van Wieringen, P. C. W. (1990). Timing an Attacking Forehand Drive in Table Tennis. Journal of Experimental Psychology: Human Perception and Performance, 16(1), 21-29. doi:10.1037/0096-1523.16.1.21

Davids, K., Button, C., \& Bennett, S. (2008). Dynamics of skill acquisition. Champaign, IL: Human Kinetics.

Dicks, M., Davids, K., \& Button, C. (2010). Individual differences in the visual control of intercepting a penalty kick in association football. Human Movement Science, 29(3), 401-411. doi:10.1016/j.humov. 2010.02.008

Elliott, B., Baker, J., \& Foster, D. (1993). The kinematics and kinetics of the off-drive and on-drive in cricket. Australian Journal of Science and Medicine in Sport, 25(2), 48-54.

Field, A. (2009). Discovering Statistics Using SPSS (3rd ed.). London, UK: SAGE Publications.

Fortenbaugh, D., Fleisig, G., Onar-Thomas, A., \& Asfour, S. (2011). The effect of pitch type on ground reaction forces in the baseball swing. Sports Biomechanics, 10(4), 270-279. doi:10.1080/14763141.2011. 629205

Hubbard, A. W., \& Seng, C. N. (1954). Visual movements of batters. Research Quarterly for Exercise and Sport, 25(1), 42-57. doi:10. 1080/10671188.1954.10624942

Katsumata, H. (2007). A functional modulation for timing a movement: A coordinative structure in baseball hitting. Human Movement Science, 26(1), 27-47. doi:10.1016/j.humov.2006.09.005

Land, M. F., \& McLeod, P. (2000). From eye movements to actions: Batsmen hit the ball. Nature Neuroscience, 3(12), 1340-1345. doi: $10.1038 / 81887$

Mattos, D., Kuhl, J., Scholz, J. P., \& Latash, M. L. (2013). Motor equivalence (ME) during reaching: Is ME observable at the muscle level? Motor Control, 17(2), 145-175. doi:10.1007/s00221-007-1101-2

Mattos, D. J. S., Latash, M. L., Park, E., Kuhl, J., \& Scholz, J. P. (2011). Unpredictable elbow joint perturbation during reaching results in multijoint motor equivalence. Journal of Neurophysiology, 106(3), 1424-1436. doi:10.1152/jn.00163.2011

Müller, S., \& Abernethy, B. (2006). Batting with occluded vision: An in situ examination of the information pick-up and interceptive skills of high- and low-skilled cricket batsmen. Journal of Science and Medicine in Sport, 9(6), 446-458.

Müller, S., \& Abernethy, B. (2008). Validity and reliability of a simple categorical tool for the assessment of interceptive skill. Journal of Science and Medicine in Sport, 11(6), 549-552.

Müller, S., \& Abernethy, B. (2012). Expert anticipatory skill in striking sports: A review and a model. Research Quarterly for Exercise and Sport, 83(2), 175-187.

Müller, S., Abernethy, B., Reece, J., Rose, M., Eid, M., McBean, R., \& Abreu, C. (2009). An in-situ examination of the timing of information pick-up for interception by cricket batsmen of different skill levels. Psychology of Sport and Exercise, 10(6), 644-652.

Müller, S., Lalović, A., Dempsey, A. R., Rosalie, S., \& Harbaugh, A. G. (2014). Pick-up of early visual information to guide kinetics and kinematics within a group of highly skilled baseball batters. Perceptual and Motor Skills, 119(2), 347-362.
Newell, K. M. (1986). Constraints on the development of coordination. In M. G. Wade \& H. T. A. Whiting (Eds.), Motor development in children: Aspects of coordination and control (pp. 341-360). The Hague, The Netherlands: Nijhoff.

Perneger, T. V. (1998). What's wrong with Bonferroni adjustments (Vol. 316).

Pinder, R. A., Davids, K., \& Renshaw, I. (2012). Metastability and emergent performance of dynamic interceptive actions. Journal of Science and Medicine in Sport, 15(5), 437-443. doi:10.1016/j. jsams.2012.01.002

Pinder, R. A., Renshaw, I., \& Davids, K. (2009). Information-movement coupling in developing cricketers under changing ecological practice constraints. Human Movement Science, 28(4), 468-479. doi:10. 1016/j.humov.2009.02.003

Portney, L. G., \& Watkins, M. P. (2009). Foundations of clinical research: Applications to practice (3rd ed.). New Jersey: Pearson Prentice Hall.

Rosalie, S. M., \& Müller, S. (2013). Timing of in situ visual information pick-up that differentiates expert and near-expert anticipation in a complex motor skill. Quarterly Journal of Experimental Psychology, 66(10), 1951-1962. doi:10.1080/17470218.2013. 770044

Schöllhorn, W. I., Nigg, B. M., Stefanyshyn, D. J., \& Liu, W. (2002). Identification of individual walking patterns using time discrete and time continuous data sets. Gait and Posture, 15(2), 180-186. doi:10. 1016/S0966-6362(01)00193-X

Shim, J., Carlton, L. G., Chow, J. W., \& Chae, W. S. (2005). The use of anticipatory visual cues by highly skilled tennis players. Journal of Motor Behavior, 37(2), 164-175. doi:10.3200/jmbr. 37.2.164-175

Stuelcken, M. C., Portus, M. R., \& Mason, B. R. (2005). Off-side front foot drives in men's high performance cricket. Sports biomechanics / International Society of Biomechanics in Sports, 4(1), 17-35.

Taylor, J. L., Kennedy, Q., Noda, A., \& Yesavage, J. A. (2007). Pilot age and expertise predict flight simulator performance: A 3-year longitudinal study. Neurology, 68(9), 648-654. doi:10.1212/01.wnl. 0000255943.10045.c0

Uehara, L., Button, C., Falcous, M., \& Davids, K. (2014). Contextualised skill acquisition research: A new framework to study the development of sport expertise. Physical Education and Sport Pedagogy. doi:10.1080/17408989.2014.924495

Vickers, J. N., \& Lewinski, W. (2012). Performing under pressure: Gaze control, decision making and shooting performance of elite and rookie police officers. Human Movement Science, 31(1), 101-117. doi:10.1016/j.humov.2011.04.004

Weissensteiner, J. R., Abernethy, B., \& Farrow, D. (2011). Hitting a cricket ball: What components of the interceptive action are most linked to expertise? Sports Biomechanics, 10(4), 324-338.

Wilson, M., McGrath, J., Vine, S., Brewer, J., Defriend, D., \& Masters, R. (2010). Psychomotor control in a virtual laparoscopic surgery training environment: Gaze control parameters differentiate novices from experts. Surgical Endoscopy and Other Interventional Techniques, 24(10), 2458-2464. doi:10.1007/s00464-010-0986-1

Wood, J. M., Horswill, M. S., Lacherez, P. F., \& Anstey, K. J. (2013). Evaluation of screening tests for predicting older driver performance and safety assessed by an on-road test. Accident Analysis and Prevention, 50, 1161-1168. doi:10.1016/j.aap.2012.09.009

Yarrow, K., Brown, P., \& Krakauer, J. W. (2009). Inside the brain of an elite athlete: The neural processes that support high achievement in sports. Nature Reviews Neuroscience, 10(8), 585-596. doi:10.1038/ nrn 2672 